\title{
Bilateral femoral neck fractures in an adult male following minimal trauma after a simple mechanical fall: a case report Asheesh Sood ${ }^{1}$, Christopher Rao*2 and Ian Holloway ${ }^{1}$
} \author{
Imperial College London, 5 Cheerytree House, Droop Street, London W10 4EL, UK \\ Email: Asheesh Sood - soodasheesh@ @otmail.com; Christopher Rao* - christopher.rao@imperial.ac.uk; \\ Ian Holloway - ian.holloway@nwlh.nhs.uk \\ * Corresponding author
}

Address: ${ }^{1}$ Northwick Park Hospital, Watford Road, Harrow, Middlesex HA1 3UJ, UK and ${ }^{2}$ Department of Biosurgery and Surgical Technology,

Published: 28 January 2009

Cases Journal 2009, 2:92 doi:10.1186/1757-1626-2-92

This article is available from: http://www.casesjournal.com/content/2/1/92

(C) 2009 Sood et al; licensee BioMed Central Ltd.

This is an Open Access article distributed under the terms of the Creative Commons Attribution License (http://creativecommons.org/licenses/by/2.0), which permits unrestricted use, distribution, and reproduction in any medium, provided the original work is properly cited.
Received: 17 January 2009

Accepted: 28 January 2009

\begin{abstract}
Background: Despite being rare there are several reports in the medical literature of bilateral femoral neck fractures in adult patients. They have been reported to have occurred following major trauma, or as a result of primary or secondary bone disease. In this case report we describe for the first time in the literature bilateral femoral neck fractures in a patient following minimal trauma after a simple mechanical fall.

Case presentation: We describe the case of an 84-year-old gentleman who sustained bilateral intracapsular fractures following a simple mechanical fall. Prompt diagnosis and early surgical intervention resulted in a satisfactory outcome.

Conclusion: This case highlights that in the elderly, even in the absence of primary and secondary bone disease, bilateral neck of femur fractures can occur following relatively minor trauma. Consequently, the orthopaedic surgeon, emergency physician and general practitioner should be aware of this injury, particularly when managing traumatic injuries in confused patients.
\end{abstract}

\section{Background}

Bilateral fractures of the Neck of the Femur (NOF) have been reported to have occurred following major trauma, or as a result of primary or secondary bone disease. We describe the case of an 84-year-old gentleman who sustained bilateral intracapsular fractured NOF following a simple mechanical fall. Early diagnosis, resuscitation, surgical intervention, post-operative mobilisation and discharge; according to best practice guidelines [1]; resulted in a satisfactory outcome.

Following a review of the published literature we undertake to discuss the importance of prompt diagnosis and early surgical treatment in achieving a satisfactory outcome following this injury. Finally, we aim to discuss the implications of this case on our routine orthopaedic practice.

\section{Case presentation}

An 84-year-old gentleman presented to the Accident and Emergency Department in the early hours of the morning after a mechanical fall down three stairs. He was an active, independent gentleman with no significant co-morbidities. He was also the full time carer for his wife who suffered from multiple sclerosis. His pre-morbid mobility was good and he did not require any walking aids. 
He was immediately resuscitated in the Accident and Emergency Department. Clinical examination revealed external rotation of both legs and pain on passive movement of both hips. X-ray of his pelvis showed completely displaced intracapsular hip fractures on both sides [Figure $1]$.

The fractures were treated by cemented hemiarthroplasty using Thompson prostheses. This was undertaken with the patient in the supine position within 24 hours of admission using an antero-lateral approach by two senior Orthopaedic surgeons [Figure 2]. He had a satisfactory post-operative recovery and was able to mobilise and fully weight-bear within 2 days of the surgery.

\section{Discussion}

Simultaneous bilateral NOF fractures are rare. They are however, several reports in the medical literature of bilateral NOF fractures occurring as a result of primary or secondary bone disease. For example, hypocalcemia [2], osteomalacia [3], osteoporosis, renal osteodystrophy [4], radiotherapy [5] and multiple myeloma. Bilateral NOF fractures have also been reported to have occurred following persistent, sustained stress [5].

Uncomplicated trauma is a rare cause of bilateral fractured NOF [6]. There have been reports of bilateral NOF fractures after seizures secondary to epilepsy, drugs, and electrocution [6]. Intracapsular fractures of the NOF prior to the fifth decade of life usually result from severe injury [5]. Konforti et al [7] described bilateral NOF fractures in a 37-year-old gentleman crushed during a mining acci-

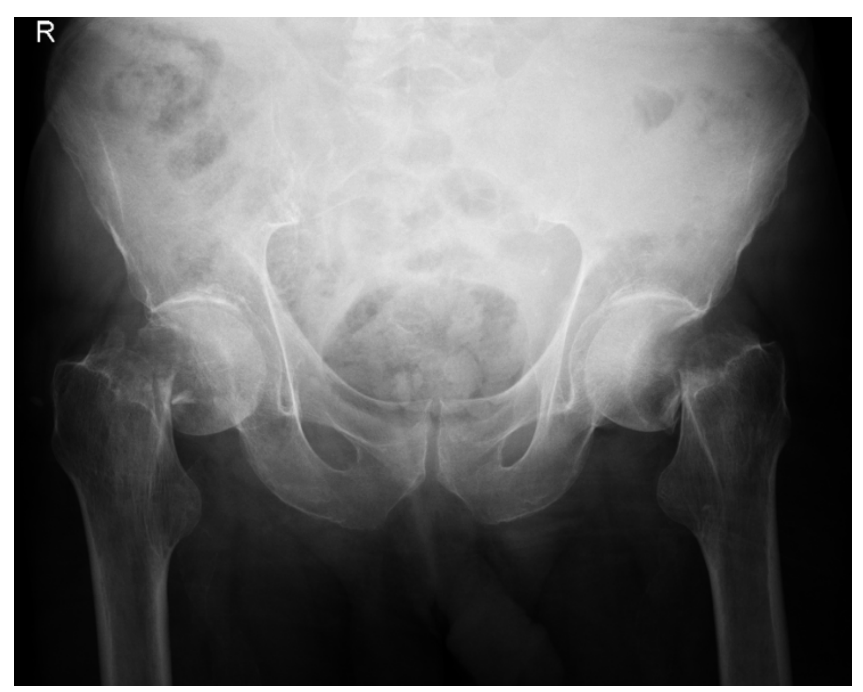

Figure I

Anterioposterior radiograph of the pelvis showing bilateral completely displaced intracapsular fractures of the neck of femur.

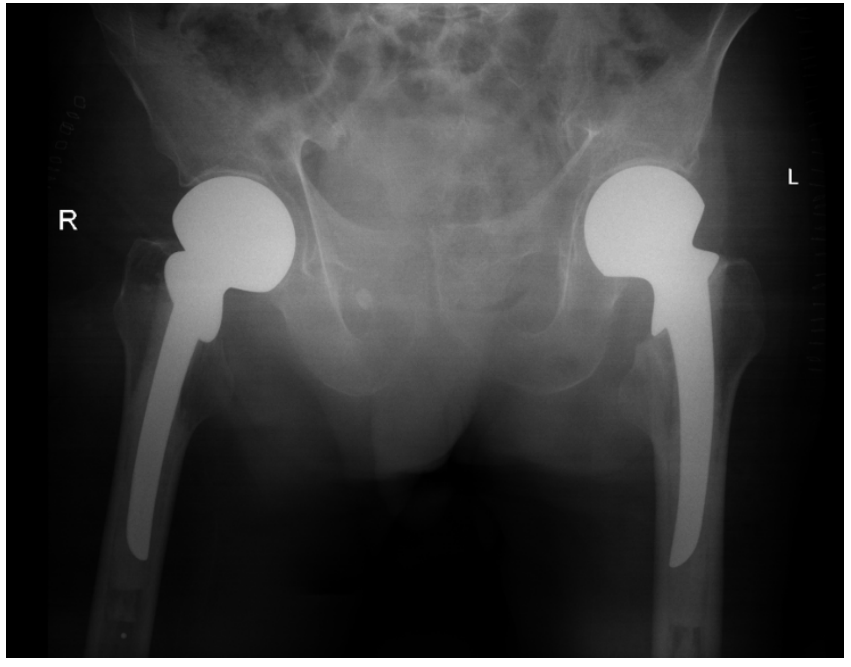

Figure 2

Anterioposterior radiograph of the pelvis showing bilateral fractures of the neck of femur treated by cemented Thompson hemiarthroplasties.

dent. Carrell et al [8] described the case of an 8 year old boy who sustained a bilateral neck fractures following a 25 foot fall. More recently Gunal et al [9] describe bilateral traumatic NOF fractures.

In the case we describe an otherwise fit and well gentleman who sustained bilateral NOF fractures following a low energy injury fall down three stairs. This is a common mechanism of injury which often leads to a unilateral NOF fracture. It is important to note that this patient gave a definite history of a fall which led to the injury in contrast to fatigue fractures [5] where patients describe their leg giving way followed by pain. Bilateral fractured NOF have been reported in the literature in the elderly following minimal trauma [10]. However, in this case described the patient had a background of corticosteroid induced osteoporosis, gross obesity and rheumatoid arthritis.

Guidelines for the management of hip fractures recommend that surgical intervention should be carried out within 48 hours of the fracture occurring [1]. As well as causing distress to the patient, delay in surgery is associated with increased morbidity and mortality, and a reduced chance of success and rehabilitation [11]. Surgery should be performed as soon as the medical condition of the patient allows, provided that appropriate staffing and facilities are available [11]. However, it has also been demonstrated that surgical treatment conducted as nighttime emergency cases are associated with increases mortality [11]. 
Our management of this patient was entirely consistent with these guidelines. The fractures were diagnosed early and the patient was resuscitated appropriately. The patient was reviewed by the physicians and anaesthetists on the day of admission and optimized medically. Both hip fractures were managed by simultaneous cemented hemiarthroplasty within 24 hours of admission on a daytime trauma list. McBryde et al [12] have demonstrated the safety of simultaneous hip arthroplasties, albeit in the context of elective surgery. The operation was performed in the supine position, to avoid repositioning the patient, in order to shorten the total operating time. There is however, no evidence to support the superior efficacy of any position and we feel the surgeon should use the position with which he is most comfortable.

All hip injuries presenting to the Accident and Emergency Department in our hospital have an anterioposterior radiograph of the pelvis with both hips included as part of initial assessment. This is an important precaution as there may be an injury of the opposite hip which could easily be missed. As a result of this case, our junior surgical staff have been trained to be particularly vigilant to the possibility of bilateral NOF fractures, particularly in the very elderly, in cases where there may be primary or secondary bone disease, when the mechanism of injury is highimpact or unknown, and when patients are confused and unable to localize pain.

\section{Conclusion}

In this case report we present a rare combination of injuries occurring simultaneously in an elderly gentleman. While a unilateral hip fracture is a very common injury managed appropriately on a regular basis by Orthopaedic surgeons, bilateral injuries of this nature presenting simultaneously can prove to be a diagnostic and therapeutic challenge. Early recognition and prompt surgical intervention can lead to good outcomes despite the severity of this injury. Bilateral anterioposterior radiographs should be taken as a matter of routine in patients presenting with suspected fractured NOF and orthopedic staff should be vigilant to the possibility of bilateral NOF fractures.

\section{Consent}

Written informed consent was obtained from the patient for publication of this case report and accompanying images. A copy of the written consent is available for review by the Editor-in-Chief of this journal.

\section{Competing interests}

The authors declare that they have no competing interests.

\section{Authors' contributions}

AS and CR were responsible for drafting the case study. IH was responsible for revising it critically for important intellectual content and was the consultant ultimately responsible for managing this patient. All authors have made substantial contribution to the conception of this case report, read and approved the final version to be submitted.

\section{References}

I. British Orthopaedic Association: The care of fragility fracture patients. London: BOA; 2003.

2. Taylor LJ, Grant SC: Bilateral fractures of the femoral neck during a hypocalcemic convulsion: A case report. J Bone Joint Surg (Br) 1985, 42:536-7.

3. Chadha M, Balain B, Maini L, Dhal A: Spontaneous bilateral displaced femoral neck fractures in nutritional osteomalacia- a case report. Acta Orthop Scand 200I, 72:94-6.

4. Gerster JC, Charhon SA, Jaeger P, Boyvyn G, Briancon D, Rostan A, Meunier PJ: Bilateral fractures of the femoral neck in patients with moderate renal failure receiving fluoride for spinal osteoporosis. Br Med J 1983, 287:723-5.

5. May VR: Simultaneous Bilateral Intracapsular Fracture of the Hips: One case due to Trauma, One of Fracture Fatigue, and One Following Pelvic Irradiation. South Med J 1964, 57:306-I I.

6. Powell HDW: Simultaneous bilateral fractures of the neck of the femur. J Bone Joint Surg(Br) 1960, 42:236-52.

7. Konforti B, Chokanov K: Simultaneous Bilateral Nailing by Two Teams of Surgeons in Fractures of the Femoral Neck. Volume 9. Khirurgiia, Sofia; 1956:75.

8. Carrell B, Carrell WB: Fractures in the Neck of the Femur in Children with Paticular Reference to Aseptic Necrosis. J Bone Joint Surg 194I, 23:225.

9. Günal I, Gürsoy Y, Arac S: Traumatic bilateral fractures of the femoral neck (a case report). Hacettepe J Orthop Surg 199I, I:4.

10. Tait GR: Simultaneous bilateral fractures of the femoral neck. Scott Med J 1988, 33:34I-2.

II. Scottish Intercollegiate Guidelines Network (SIGN): Prevention and management of hip fracture in older people, a national clinical guideline. In NHS Scotland, SIGN Edinburgh: SIGN; 2002.

12. McBryde CW, Dehne K, Pearson AM, Treacy RB, Pynsent PB: Oneor two-stage bilateral metal-on-metal hip resurfacing arthroplasty. J Bone Joint Surg (Br) 2007, 89: | | 44-8.

\begin{tabular}{|} 
Publish with Biomed Central and every \\
scientist can read your work free of charge \\
"BioMed Central will be the most significant development for \\
disseminating the results of biomedical research in our lifetime. " \\
Sir Paul Nurse, Cancer Research UK \\
Your research papers will be: \\
• available free of charge to the entire biomedical community \\
• peer reviewed and published immediately upon acceptance \\
• cited in PubMed and archived on PubMed Central \\
• yours - you keep the copyright \\
Submit your manuscript here: \\
http://www.biomedcentral.com/info/publishing_adv.asp
\end{tabular}

